\title{
Research on Innovation and Entrepreneurship Education in Higher Vocational Colleges Based on "Internet Plus"
}

\author{
Fei LIAN \\ Nanjing Vocational Institute of Technology, Nanjing China \\ 2439127660@qq.com
} Keywords: "Internet Plus", Higher Vocational Colleges, Innovation and Entrepreneurship
Education.

\begin{abstract}
The implementation of "internet plus" action plan enables internet field become the first choice of innovation and entrepreneurship of college students. The innovation and entrepreneurship education in higher vocational colleges must adjust teaching methods and teaching thinking, so that it can adapt to the strategic needs of "internet plus". This paper analyzes the impacts of "internet plus" on the innovation and entrepreneurship education of higher vocational college students and discusses the existing problems of the innovation and entrepreneurship education in higher vocational colleges based on "internet plus"; it also proposes development countermeasures of the innovation and entrepreneurship education in higher vocational colleges based on "internet plus".
\end{abstract}

\section{Introduction}

In 2015, Premier Li Keqiang first proposed "internet plus" action plan in the government report. Internet innovation and entrepreneurship were defined as the strategic height of national development, ushering in the golden age of integrated development. "Internet plus" is the new business form of internet development and the further practical practical achievement of internet thinking. It provides a broad network platform for social and economic reformation, innovation and development, becoming a new impetus for supporting social progress and economic development. Along with the continuous development of "internet plus", new requirements are proposed for innovation and entrepreneurship education in higher vocational colleges in China. From the perspective of "internet plus", entrepreneurship in colleges and universities is endowed with more substantial contents; direction of talent cultivation and construction of curriculum system will be greatly affected. Therefore, entrepreneurship education in higher vocational colleges must adjust teaching methods and teaching thinking and face "internet plus" to promote the education and teaching reformations, so that entrepreneurship education in higher vocational colleges can adapt to the strategic needs of future development of economy and society in China. The development is characterized by "internet plus".

\section{Analysis of the Impacts of "Internet Plus" on Innovation and Entrepreneurship Education of Students in Higher Vocational Colleges}

\section{“Internet Plus” Broadens Ways of Innovation and Entrepreneurship Education for Students in Higher Vocational Colleges}

The number of university undergraduates in China is on the increase year by year, so employment and entrepreneurship work of higher vocational colleges is becoming increasingly arduous. Promoting "internet plus" innovation and entrepreneurship education and cultivating new-type high-quality talents with innovation and entrepreneurship spirit, thought, capability and personality become effective means to improve employment quality of university undergraduates and promote social harmonious development. Meanwhile, increasing employment with entrepreneurship and enhancing "hematopoietic" function of "internet plus" innovation and entrepreneurship provide more internet employment positions, broadening ways of innovation and entrepreneurship for students in higher vocational colleges. 


\section{“Internet Plus" represents the Trend of Innovation and Entrepreneurship of Students in Higher Vocational Colleges}

In the innovation and entrepreneurship industry of "internet plus", college students, who depend on early contact, quick mastery and skillful application of new internet technology, turn out to be core strength of leading the trend of the times. Internet has gradually become an important platform for college students to study, live and work. In recent years, the rapidly developing network e-commerce becomes the first choice for entrepreneurs due to fast technological innovation, novel business model and convenient financing channels; it turns out to be one of the most suitable ways for students in higher vocational colleges to carry out innovation and entrepreneurship.

\section{“Internet Plus” Requires Students in Higher Vocational Colleges to Be Equipped with Internet Innovation and Entrepreneurship Capabilities}

The leap-forward development of internet economy breaks traditional economic form and initiates new business model, driving global economic development. College students serve as the important internet participants. In this connection, in order to promote international competitiveness, it becomes particularly important for college students to be equipped with innovation and entrepreneurship capabilities. The innovation and entrepreneurship education in higher vocational colleges should comply with the development law of global internet economy, organically combine innovation and entrepreneurship education and internet, and focus on cultivating the internet innovation and entrepreneurship capabilities of college students, promoting the development of internet economy in China.

\section{Features of “Internet Plus” Innovation and Entrepreneurship \\ Relatively Rapid, Simple to Operate}

First and foremost, compared with substantial start-ups, internet start-ups have low cost. Sometimes, only a computer which can be linked to network is required. Thus, the invested venture capital is greatly reduced. In the second place, the thresholds of internet start-ups are low; it is unnecessary for entrepreneurs to have a full grasp of professional knowledge. They only need to undertake short-term training or self-learning, grasping fundamental operating capabilities. At last, internet start-ups have low risks, and entrepreneurship failures give rise to less loss. Relevant investigations reveal that 120,000 individual entrepreneurs register stores with enterprise licenses on Taobao at this stage. Many of them are college undergraduates or college graduates.

\section{Convenient to Obtain Information, Conducive to Entrepreneurship}

Under the impacts of mass information, if business opportunities can not be grasped in time and limited social resources can not be obtained, the probability of venture success is difficult to be ensured. Through the internet, it is easier for college students to comprehend the development tendency of the industry, thus extending entrepreneurial platforms and enhancing the possibility of venture success.

\section{Shortening Entrepreneurship Time, Helping College Students Grow Up as Soon as Possible}

Capital, team management, and interpersonal relationship are the problems that college students face in the entrepreneurial process. Especially for college students who just graduate and come upon the stage, interpersonal relationship is the main problem which needs to be faced. However, there are fewer barriers of interpersonal communication in terms of internet start-ups. Question discussions and business negotiations can be carried out through network, so that college students can accumulate relevant experience in a short period of time, laying solid foundations for career development. 


\section{Existing Problems of Current "Internet Plus" Innovation and Entrepreneurship Education in Higher Vocational Colleges}

The "internet plus" innovation and entrepreneurship education in China is in the initial stage. Higher vocational colleges regard innovation and entrepreneurship education as a kind of survival skill of college students for cultivation and training, understanding internet innovation and entrepreneurship education as the "speed-up education" of fostering network entrepreneurs. The construction of the system rests on national call for colleges and universities, distorting the idea and connotation of innovation and entrepreneurship education.

\section{One-sided Cognition of “Internet Plus” Innovation and Entrepreneurship Education}

China strongly encourages public business innovation. However, a considerable part of higher vocational college students have insufficient cognition of innovation and entrepreneurship, lacking entrepreneurial knowledge and skills. Many students mistakenly equals internet innovation and entrepreneurship to setting up websites, doing business through kinds of Internet platforms and promoting products for making profits, and they are anxious for creating income and gaining benefits. Higher vocational colleges maintain that "internet plus" innovation and entrepreneurship education is to cultivate students' capabilities to use network and engaging in business deals, neglecting to cultivate students' innovation consciousness and entrepreneurial competence. It seriously hinders the development of "internet plus" innovation and entrepreneurship education in higher vocational colleges.

\section{Thin Foundation of "Internet Plus” Innovation and Entrepreneurship Education}

“Internet plus” action plan in China has been implemented for a short period of time. The innovation and entrepreneurship education in higher vocational colleges starts late with weak foundations, causing the outdated teaching content, single teaching form, fragmentary educational curriculum, unsubstantial faculty, scanty practice-based teachers and deficient practical teaching. In this connection, it is difficult to form substantive, systematic, and specific "internet plus" innovation and entrepreneurship education.

\section{Low Landing Rate of “Internet Plus” Innovation and Entrepreneurship Policy}

China has introduced a series of innovation and entrepreneurship policies to help the innovation and entrepreneurship of college students, providing strong guarantee for higher vocational colleges to cultivate innovative talents. However, innovation and entrepreneurship support polices tend to be merely instructive, lacking concrete and effective implementations. Imperfect support policies and unsmooth information channels cause the fact that college students of innovation and entrepreneurship are at a loss what to do in the face of various kinds of entrepreneurial problems. Therefore, some excellent projects are suffocated and come to premature ends, affecting college students' enthusiasm for innovation and entrepreneurship. Moreover, college students' dream of innovation and entrepreneurship can not come true.

\section{Strong Utility of “Internet Plus” Innovation and Entrepreneurship Education}

The target location of the public for "internet plus" innovation and entrepreneurship education shows the tendency of seeking quick success and instant benefits. Government, media and the public mainly focus on its employment function as well as the proportion of population and successful stories of "internet plus" innovation and entrepreneurship. The success rate and business volume of network start-ups are regarded as the measuring standard for "internet plus" innovation and entrepreneurship education. The concept and connotation of innovation and entrepreneurship education can not truly be rooted in the hearts of the people and recognized by most college students, teachers and colleges. Utilitarian value orientation contorts the evaluation and orientation of internet innovation and entrepreneurship education. 


\section{Development Countermeasures of Innovation and Entrepreneurship Education in Higher Vocational Colleges Based on "Internet Plus"}

\section{Setting New Thinking of “Internet Plus” Innovation and Entrepreneurship}

The rapid development and popularization of internet technology change people's traditional styles of life, work and study as well as the demand of human resource in the market. The impacts of Internet on employment market and entrepreneurial environment should be fully realized in the cultivation process of innovation and entrepreneurship capabilities. During the selection process, innovative ideas and innovation programs should correspond to the era background of "internet plus", and internet advantages should be utilized, constructing management system of schools, colleges, and students. Individual demand difference of students should be taken as the starting point. Through the individualized learning of students, students should be helped to clarify their own entrepreneurial positions, improving the pertinence and effectiveness of innovation and entrepreneurship education.

\section{Constructing a New Three-dimensional Innovation and Entrepreneurship Education Model}

“Trinitarian” innovation and entrepreneurship education model should be constructed. Trinity indicates "theoretical foundation plus simulative practice plus emphasis on actual combat". This kind of education model is based on professional education. Classroom teaching, simulative practice and post practice should be integrated with each other. Comprehensive practical training of professional competence can be conducted with the aid of instructional software of information technology, so that students can know the entrepreneurship process and practice methods of enterprise operation. That is how to improve students' success rate of entrepreneurship practice.

\section{Perfecting “Internet Plus” Innovation and Entrepreneurship Platform}

The construction of "internet plus" entrepreneurship practice can be perfected, from the perspective of "theoretical knowledge plus simulative practice plus emphasis on actual combat". Real-time exchange, communication and sharing of information can be carried out with the aid of internet platform. Internet technology should be applied to construct the platform of information sharing and feedback. Diversified teaching techniques and methods should be integrated with the "internet plus" thinking. Students' idea cultivation and entrepreneurial practice of innovation and entrepreneurship should be extended from in-class to after-class. The integrative practice of idea conception, project research, and incubation should be accomplished.

Under the era background of "internet plus", the innovation and entrepreneurship issue of college students should fully integrate social resources, rather than simply rely on the "one-sided advances" of colleges and college students. The idea that "innovation promotes entrepreneurship and entrepreneurship increases employment" should be always stuck to. Internet can be used to build up informationalized platform, integrating and sharing social resources. Through setting up "innovation and entrepreneurship center", matched safeguard policies and measures should be formulated to build innovation and entrepreneurship platforms and, promoting and implementing chained development pattern of "education, practice, incubation and research". The innovation and entrepreneurship education in universities and colleges can depend on university science parks and innovation and entrepreneurship clubs of college students, constructing perfect innovation and entrepreneurship education system and incubation support system of college students. The innovation and entrepreneurship education reform should be integrated into teaching reform, and the participation degree of students and teachers should be improved. In doing so, the ultimate goal of innovation and entrepreneurship education can be achieved and national innovation strategies can be driven.

\section{Improving Students' Practical Abilities of “Internet Plus” Innovation and Entrepreneurship}

Along with the continuous development of "internet plus" business form, competitions between e-commerce enterprises also becomes increasingly fierce. Supposing that college students desire to carry out innovation and entrepreneurship activities in the mode of "internet plus", they should not only have clear understandings of development of "internet plus" business form. More importantly, they must be equipped with strong practical abilities. Firstly, the constructions of practice platforms 
for innovation and Entrepreneurship should be strengthened. In the face of "internet plus", the constructions of practical teaching platforms should be continuously enhanced. Capital investment should be increased and hardware facilities should be perfected, in order to provide innovation and entrepreneurship places for students. The "internet plus" entrepreneurship environment should be furthest simulated, providing carriers for students to carry out innovation and entrepreneurship activities. Secondly, innovation and entrepreneurship support should be enhanced. Numerous higher vocational colleges should be established in the development characteristics of "internet plus" and objective conditions of students' innovation and entrepreneurship activities to make supportive policies for students, so that students can more efforts and wisdoms on "internet plus" innovation and entrepreneurship activities. Thirdly, collaboration should be established with large-scale e-commerce enterprises. Students should be transported to practice in e-commerce enterprises. E-commerce managers should be invited to serve as part-time teachers. Large-scale e-commerce resources should be employed for practical teaching. It is helpful for students to enhance their understandings of "internet plus" business form and enhance their practical abilities of innovation and entrepreneurship.

\section{Summary}

As "internet plus" business form continuously develops, innovation and entrepreneurship education in higher vocational colleges should face, adapt to and center on "internet plus" to adjust theory teaching and construct practical teaching system, provide professional services for "internet plus" innovation and entrepreneurship education activities of students and build practical platforms. College students' comprehensive qualities should be constantly improved for innovation and entrepreneurship education activities, promoting the realization of new development innovation and entrepreneurship education in higher vocational colleges.

\section{References}

[1]Guan Jianwen, Li Lidan. "Internet Plus": Power of Reconstruction .Modern Media (Journal of Communication University of China), 2015, (6)(In Chinese)

[2]Chen Xiaozhu. Innovation and Entrepreneurship Education in Universities in the Era of Everyone .China Higher Education, 2015(13) (In Chinese)

[3]Ning Jiajun. The Implementation Background, Connotation and Main Contents of "Internet Plus" Action Plan .E-government Affairs, 2015, (6) (In Chinese)

[4]Chen Yong. Exploration into Innovation and Entrepreneurship Education in Higher Vocational Colleges from the Perspective of "Internet Plus" .Journal of Southern Vocational Education, 2016 (2) (In Chinese)

[5]Ni Jingjing. Curricula Design of Local Innovation and Entrepreneurship Education in Vocational Colleges from the Perspective of Fusion .Journal of Anhui Agricultural University (Social Science Edition), 2016(2) (In Chinese) 